\title{
The Emotional State of Technology Acceptance
}

\author{
Raafat George Saadé \& Dennis Kira \\ John Molson School of Business, Concordia University \\ Montreal, Quebec, Canada
}

rsinfo@sympatico.ca kira@vax2.concordia.ca

\begin{abstract}
Computer-phobic university students are easy to find today especially when it come to taking online courses. Affect has been shown to influence users' perceptions of computers. Although self-reported computer anxiety has declined in the past decade, it continues to be a significant issue in higher education and online courses. More importantly, anxiety seems to be a critical variable in relation to student perceptions of online courses. A substantial amount of work has been done on computer anxiety and affect. In fact, the technology acceptance model (TAM) has been extensively used for such studies where affect and anxiety were considered as antecedents to perceived ease of use. However, few, if any, have investigated the interplay between the two constructs as they influence perceived ease of use and perceived usefulness towards using online systems for learning. In this study, the effects of affect and anxiety (together and alone) on perceptions of an online learning system are investigated. Results demonstrate the interplay that exists between affect and anxiety and their moderating roles on perceived ease of use and perceived usefulness. Interestingly, the results seem to suggest that affect and anxiety may exist simultaneously as two weights on each side of the TAM scale.
\end{abstract}

Keywords: Affect; Anxiety; TAM; Perceived Usefulness; Ease of Use; Online Learning

\section{Introduction}

Recently, interest in the use of online learning tools has increased significantly. The value of online learning has become widely accepted as an approach to enhance the classroom environment. Ever since Ivari and Ervasti, (1994) stated that productivity gains and benefits to students and academic institutions promised by learning technologies cannot be realized unless they are effectively used. In fact, little research today is being done on effectiveness in online learning. Most of this research is done on acceptance which has also been identified as a critical issue in the successful usage of the learning technologies (Deci \& Ryan, 1985).

Many theoretical frameworks have been used to measure technology usage satisfaction, however relatively few have been used in the online learning context. The technology acceptance model

(TAM), has been recently used to study

Material published as part of this publication, either on-line or in print, is copyrighted by the Informing Science Institute. Permission to make digital or paper copy of part or all of these works for personal or classroom use is granted without fee provided that the copies are not made or distributed for profit or commercial advantage AND that copies 1) bear this notice in full and 2) give the full citation on the first page. It is permissible to abstract these works so long as credit is given. To copy in all other cases or to republish or to post on a server or to redistribute to lists requires specific permission and payment of a fee. Contact Publisher@InformingScience.org to request redistribution permission. the acceptance of computer-assisted applications (Saadé, 2003, 2005). In general, the TAM theorizes that perceived usefulness (PU) influences attitudes towards technology usage (ATT) and is an important determinant of individuals' intentions to use the technology. The goal of TAM is "to provide an explanation of the determinants of computer acceptance that is in general, capable of 
explaining user behavior across a broad range of end-user computing technologies and user populations, while at the same time being both parsimonious and theoretically justified" (Davis, 1986, 1989; Davis, Bagozzi, \& Warshaw, 1989).

Many researchers have worked on the extension of TAM model to fit different contexts. We follow that line of investigation to further provide additional understanding of the role of anxiety (ANX) and affect (AFF) as antecedents to the perceived ease of use and perceived usefulness constructs in TAM. We provide results related to the impact of affect and anxiety on perceived ease of use. Our study involves 114 students that used an online learning system (OLS) (developed in-house) as part of an introductory course in management information systems (MIS). Prior research in information systems has investigated the TAM constructs with affect and anxiety (Agarwal \& Karahanna, 2000; Howard \& Smith, 1986; Vallerand, 1997; Venkatesh \& Davis, 2000), however, few studies, have applied it to an online learning system and have directly compared and contrasted the impact of anxiety and affect constructs on PU and PEU to further understand the PU-PEU relationship in TAM.

\section{Theoretical Background and Research Hypothesis}

\section{The Technology Acceptance Model - TAM}

Online learning is perceived by many to be a significant breakthrough in teaching and learning (Debourgh, 1995; Johanson, 1999; Keeney, 1999; Keller, 1983; \& LaRose, Gregg, \& Eastin, 1998). The Internet allows educators to provide learners with new and innovative virtual environments in an attempt to stimulate and enhance their learning process (Brown, 2002). In addition, Internet or web technologies are important because they support manipulation of information, facilitate/enhance communications among instructors and learners and provide tools to encourage creativity and initiative (Conlon, 1997; Mioduser et al., 2000).

Studies of learners' satisfaction are typically limited to one-dimensional post-training perceptions of learners (Johnson, Aragon, Shaik, \& Palma-Rivas, 2000). Acceptance and satisfaction however, is multidimensional and includes a wide variety of critical variables including (but not limited to) perceptions, beliefs, attitudes, learners' characteristics, and level of involvement with the online course material (Chang \& Cheung, 2001). If Internet-based learning environments are to benefit students then it is important from the student's perspective that they are not seen as overly complex and hard to use. The introduction of Internet-based learning environments may hinder the learning process if the technology is perceived as being complex and not useful to enhanced performance, and thus a distraction to learning. In line with acceptance and satisfaction studies, TAM is used as the basic theoretical foundation for this research work.

According to TAM, a student's intention to use a specific OLS is jointly determined by one's attitude toward using the system and PU of the system. This implies that when the OLS is perceived to be easier to use, the greater will be the student's perceived ability to use the OLS successfully and hence perform better in the course. TAM also emphasizes the importance of how external variables can affect the student's internal decision process when it comes to using an OLS within the university. External variables affect PU directly or indirectly through PEU since it influences the student's near-term perception of usefulness and to the lesser extent long-term (Compeau, Higgins, \& Huff, 1999). Extrapolating from the study by Lucas and Spitler (1999) study, interaction between the different OLSs, direct experience with an OLS, OLS characteristics (Chau, 1996), and level of domain pre-requisite knowledge determine the student's perception of ease of use of an OLS. According to previous studies efficacy, intrinsic motivation, cognitive absorption and computer anxiety were all determinants of PEU (Gefen, Karahanna, \& Straub, 2003a, 2003b; Gefen \& Straub 1997: Pedersen and Nysveen 2003). Saadé (2003, 2005) considered student traits 
to study their mediating effects on the impact of perceived usefulness on attitudes to learning tools usage as well as the explanatory capability of the technology acceptance model. In addition to these findings they have observed that PEU and PU, to some extent, are influenced by external variables. Extensions to TAM have been introduced by Venkatesh and Davis (2000), and Venkatesh and Morris (2000) with comprehensive study of the determinants of perceived ease of use. Extension to the theory, proposed control, intrinsic motivation (playfulness), and emotion (anxiety) as anchors that influence users' early perceptions about system ease of use. These models were strongly supported by the empirical results and indicated that up to $60 \%$ of the variability of PEU is explained in this model (Venkatesh \& Morris, 2000).

\section{Affect}

The term Affect consists of four dimensions: cognitive, affective, behavioral and perceived control. The cognitive component focuses on belief, for example, whether or not a person believes that computers can increase significantly the quality of their output. The affective component is the emotion or feeling concerned with how much the computer is liked, and the behavioral component of the attitude relates to what an individual actually does or intends to do with the technology. The fourth dimension considers the perceived control dimensions of computer attitudes, that is, "the perceived ease or difficulty of performing a particular behavior'. By taking affect into account we should be able to explain more variance in users' intention and behavior (e.g. Davis, Bagozzi \& Warshaw, 1992). In this study we consider the affective component. Affective refers to an individual's feelings of joy, elation, pleasure, depression, distaste, discontentment, or hatred with respect to a particular behavior (Triandis, 1980). Triandis argued that previous research showed a strong relationship between affect and behavior. Positive affect towards a learning tool leads to gaining experience, knowledge and self-efficacy regarding usage, and negative affect causes students to avoid the leaning tool, thereby not developing actual control (Arkkelin, 2003).

Smith Caputi, Crittenden, Jayasuriya, and Rawstone (1999) show evidence indicating support for the bi-dimensional conceptualization of the computer experience construct. They suggest that the objective computer experience and subjective computer experience measures are to be explored independently. In the same study, however, the difficulties in separating the subjective computer experience and computer attitude measures due to their similar content are indicated.

\section{Anxiety}

Use of technology in general often has unpleasant side effects, which may include strong, negative emotional states that arise during interaction with computers. Frustration, confusion, anger, anxiety and similar emotional states can affect not only the interaction itself, but also productivity, learning, social relationships, and overall well-being. There are a number of related definitions explaining as to what is anxiety. Other researchers define computer anxiety as a state of mind of being fearful or apprehensive when using or considering the use of a computer. Evidently, factors such as who may have initiated the person to the computer technology (Brosnan, 1998) past failure or successes with hardware or software; and the current tasks being attempted including the new computer applications. These researchers have attempted to predict those who will experience computer anxiety by identifying factors that correlate with its occurrence. Frequently, such factors as age, gender, ethnicity, previous computer experience, mathematics anxiety, self-efficacy, learning styles, and computer attitude are posited as factors influencing the computer anxiety.

There are three types of anxieties: trait, state, and concept-specific. Trait anxiety is defined as a general pervasive anxiety that is experienced by a person over the entire range of life experience. People who exhibit trait anxiety are chronically anxious and constantly under tension regardless 
of their situation. This anxiety is frequently used as a construct for personality, learning theory, and psychopathology. Trait anxiety has been studied because of the possible correlation between it and computer anxiety. Since several studies found a significant correlation between math anxiety and trait anxiety the natural extension is to consider a possible correlation between trait and computer anxieties. Concept-specific anxiety is the range between the trait and state anxieties. It is an anxiety that is associated with a specific situation. Therefore, computer anxiety is a conceptspecific anxiety because it is a feeling that is associated with a person's interaction with computers. In fact, Howard (1986) defines computer anxiety as the tendency of a person to experience a level of uneasiness over his or her impending use of a computer.

Understanding the variables that cause students to hold certain beliefs about an OLS would be of substantial value to students, institutions, businesses and instructors alike. It would also provide valuable insight for the successful design, implementation, and deployment of OLSs.

The research model used here is shown in Figure 1. This captures affect and anxiety as antecedents to PU and PEU for OLS. The two belief constructs in turn influence attitudes towards using different OLSs.

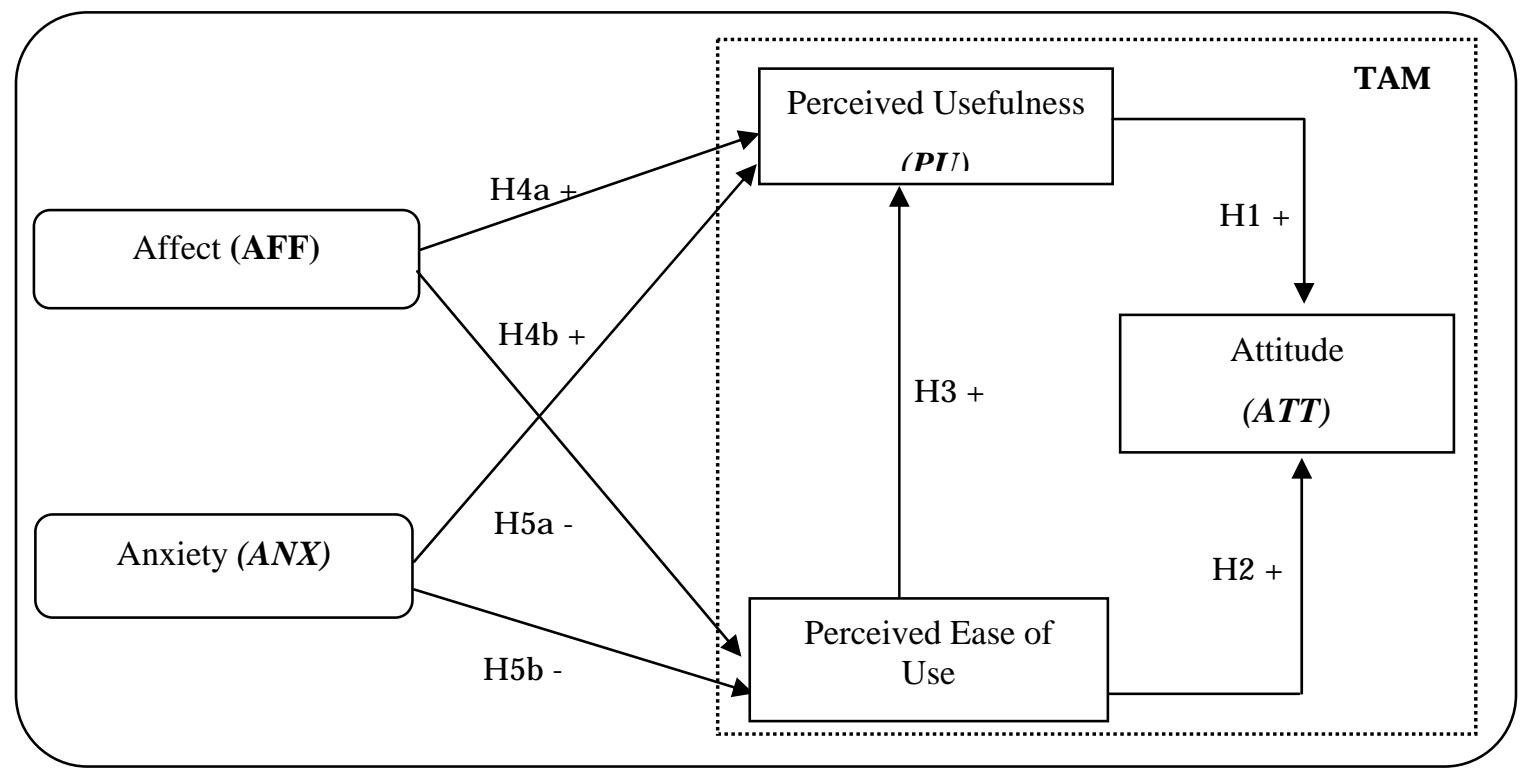

Figure 1. The Research model.

Based on the discussion above and considering that affect and anxiety may impact PU and PEU and that this impact varies depending on the characteristics of the IS (in the present case the IS is the OLS) used and the context it is used, we hypothesize that

H1. PU will have a positive relationship with ATT.

H2. PEU will have a positive relationship with ATT.

H3. PEU will have a positive relationship with $P U$

H4a. AFF will have a positive relationship with PU.

H4b. AFF will have a positive relationship with PEU.

H5a. ANX will have a negative relationship with PU.

H5b. ANX will have a negative relationship with PEU. 


\section{The Study}

The study was conducted in an undergraduate course setting spanning one semester, using a webbased learning system which was developed in-house. Throughout one semester, students in an introductory management of information systems course at the John Molson School of Business used the OLS as part of the course requirements. The use of the OLS was therefore mandatory and was worth $5 \%$ of the final grade. The objective of the OLS was to help students practice course topics via interactive multiple choice and true or false questions. The system monitored the students' activities by storing the time spent on the system, the chapters practiced, and scores.

At the end of the semester, a survey instrument was administered containing 18 items shown in table 1 below for the 5 constructs given in Figure 1. One hundred and fourteen students participated in this study. The students were practically equally distributed among gender with a mean age of 23 years. The students had an average of 2 years of work experience, use the Internet close to one hour a day and claim to have strong knowledge of basic software utilization.

Items (presented in Table 1) used to measure the constructs were adopted from prior research work. The wording of the items was changed to account for the context of using the OLS. All items were measured using a five-point Likert-type scale with anchors from "Strongly disagree" to "Strongly agree".

\section{Table1. Measures of study variables}

\begin{tabular}{|c|c|c|}
\hline Construct & Item & Measure \\
\hline \multirow[t]{3}{*}{ Perceived Usefulness (PU) } & PU1 & Using the OLS would reduce my ability to perform well in the course? \\
\hline & PU2 & $\begin{array}{l}\text { I think that an OLS such as this one should be part of each and every } \\
\text { course in the university. }\end{array}$ \\
\hline & PU3 & $\begin{array}{l}\text { Using the OLS in the course would enhance my performance in the } \\
\text { course. }\end{array}$ \\
\hline \multirow[t]{4}{*}{ Perceived Ease of Use (PEU) } & PEU1 & I think that learning to navigate the OLS will be easy for me. \\
\hline & PEU2 & $\begin{array}{l}\text { I think that I will find it easy to get the OLS to do what I want them to } \\
\text { do. }\end{array}$ \\
\hline & PEU3 & $\begin{array}{l}\text { I think that it would be easy for me to become skillful at using the } \\
\text { OLS. }\end{array}$ \\
\hline & PEU4 & I think that I will find the OLS easy to use. \\
\hline \multirow[t]{2}{*}{ Attitudes (ATT) } & ATT1 & The advantages of the OLS outweigh the disadvantages. \\
\hline & ATT2 & OLSs are not helpful for understanding better the course content. \\
\hline \multirow[t]{5}{*}{ Affect (AFF) } & AFF1 & I like working with computers. \\
\hline & AFF2 & $\begin{array}{l}\text { I look forward to those aspects of my course work that require me to } \\
\text { use a computer. }\end{array}$ \\
\hline & AFF3 & Once I start working on a computer, I find it hard to stop. \\
\hline & AFF4 & Using a computer is frustrating for me. \\
\hline & AFF5 & I get bored quickly when working on a computer. \\
\hline \multirow[t]{4}{*}{ Anxiety (ANX) } & ANX1 & I feel apprehensive about using computers. \\
\hline & ANX2 & $\begin{array}{l}\text { It scares me to think that I could cause the computer to destroy a large } \\
\text { amount of information by hitting the wrong key. }\end{array}$ \\
\hline & ANX3 & $\begin{array}{l}\text { I hesitate to use a computer for fear of making mistakes I cannot cor- } \\
\text { rect. }\end{array}$ \\
\hline & ANX4 & Computers are somewhat intimidating to me. \\
\hline
\end{tabular}




\section{Results, Analysis and Findings}

The Cronbach's alpha coefficient for internal consistency reliability was first assessed. As summarized in Table 2, the reliability of most of all constructs was acceptable with values above 0.7 (Nunnally, 1978).

Table 2. Reliability assessment.

\begin{tabular}{llll}
\hline Variables & Cronbach alpha, & Mean & SD \\
\hline Perceived Ease of Use (PEU) & 0.929 & 3.60 & 1.00 \\
\hline Perceived Usefulness (PU) & 0.821 & 3.76 & 0.67 \\
\hline Attitude (ATT) & 0.823 & 3.16 & 0.48 \\
Affect (AFF) & 0.901 & 3.59 & 1.14 \\
Anxiety (ANX) & 0.879 & 2.34 & 1.21 \\
\hline
\end{tabular}

Second, reliabilities of individual items were assessed by examining the loadings of the items on their respective constructs (table 3). These loadings should be higher than 0.5 , following the criterion indicated by Pedersen and Nysveen (2003) to indicate that significant variance was shared between each item and the construct. It is expected that the loadings of all items within a construct should be high on that construct, indicating high convergent validity, and low on the others. The factors were extracted using the principal components method (varimax rotation) which is an optimum approach to condensation prior to rotation. Table 3 clearly shows that the five-factor solution is appropriate and the items display desirable convergent and discriminant validity.

Table 3. Factor analysis

\begin{tabular}{cccccc} 
& Factor 1 & Factor $\mathbf{2}$ & Factor $\mathbf{3}$ & Factor $\mathbf{4}$ & Factor 5 \\
\hline PEU1 & 0.291 & $\mathbf{0 . 7 8 0}$ & 0.206 & 0.270 & 0.270 \\
PEU2 & 0.169 & $\mathbf{0 . 9 1 7}$ & 0.189 & 0.095 & 0.095 \\
PEU3 & 0.319 & $\mathbf{0 . 7 1 6}$ & 0.104 & 0.156 & 0.156 \\
PEU4 & 0.133 & $\mathbf{0 . 8 2 5}$ & 0.211 & 0.225 & 0.225 \\
PU1 & -0.040 & 0.107 & 0.170 & $\mathbf{0 . 5 5 8}$ & -0.188 \\
PU2 & 0.061 & 0.032 & 0.020 & $\mathbf{0 . 8 8 0}$ & -0.109 \\
PU3 & 0.053 & 0.314 & 0.032 & $\mathbf{0 . 8 1 4}$ & -0.093 \\
ATT1 & 0.041 & 0.276 & 0.108 & 0.413 & $\mathbf{- 0 . 5 3 6}$ \\
ATT2 & 0.067 & 0.083 & 0.200 & 0.280 & $-\mathbf{0 . 7 2 8}$ \\
AFF1 & 0.363 & 0.199 & $\mathbf{0 . 7 2 4}$ & 0.316 & 0.316 \\
AFF2 & 0.401 & 0.207 & $\mathbf{0 . 8 1 1}$ & -0.027 & -0.027 \\
AFF3 & 0.149 & 0.128 & $\mathbf{0 . 7 6 4}$ & 0.097 & 0.097 \\
AFF4 & 0.498 & 0.335 & $\mathbf{0 . 4 5 0}$ & 0.272 & 0.272 \\
AFF5 & 0.517 & 0.175 & $\mathbf{0 . 5 9 3}$ & 0.191 & 0.191 \\
ANX1 & $\mathbf{- 0 . 5 8 0}$ & 0.638 & -0.276 & -0.121 & -0.121 \\
ANX2 & $\mathbf{- 0 . 7 7 4}$ & 0.810 & -0.226 & -0.156 & -0.156 \\
ANX3 & $\mathbf{- 0 . 8 1 2}$ & 0.848 & -0.057 & -0.191 & -0.191 \\
ANX4 & $\mathbf{- 0 . 8 2 2}$ & 0.814 & -0.105 & -0.139 & -0.139 \\
\hline
\end{tabular}

In specific, Table 3 highlights in bold style the values higher than 0.5 (in each column), thereby indicating that the items used for the specific construct belong together and measure the same variable. For example, if we consider PU, we find that PU1 loads low with respect to PU2 and PU3 but can still be accepted based on the criteria explained above. The shaded part in the table 
identifies items that did not meet the criteria of factor analysis. The loading of AFF4 falls below 0.5 at a value of 0.45 and AFF5 loads above 0.5 on two factors namely factor 1 and 3 . In this case if further analysis is to be done AFF4 and AFF5 can be dropped.

Third, the partial least squares (PLS) method was used for the assessment of the structural model of Figure 1. Each hypothesis was tested using PLS Graph and by looking at the path coefficients. All estimated path effects were found to have a degree of significance of less than or equal to 0.05. A bootstrapping procedure was used to assess the level of significance of the paths computed by PLS.

In our PLS analysis, we ran the model four times: TAM alone, complete model as per Figure 1 (TAM \pm ), excluding the effect of anxiety (TAM + ) and excluding the effect of affect (TAM -).

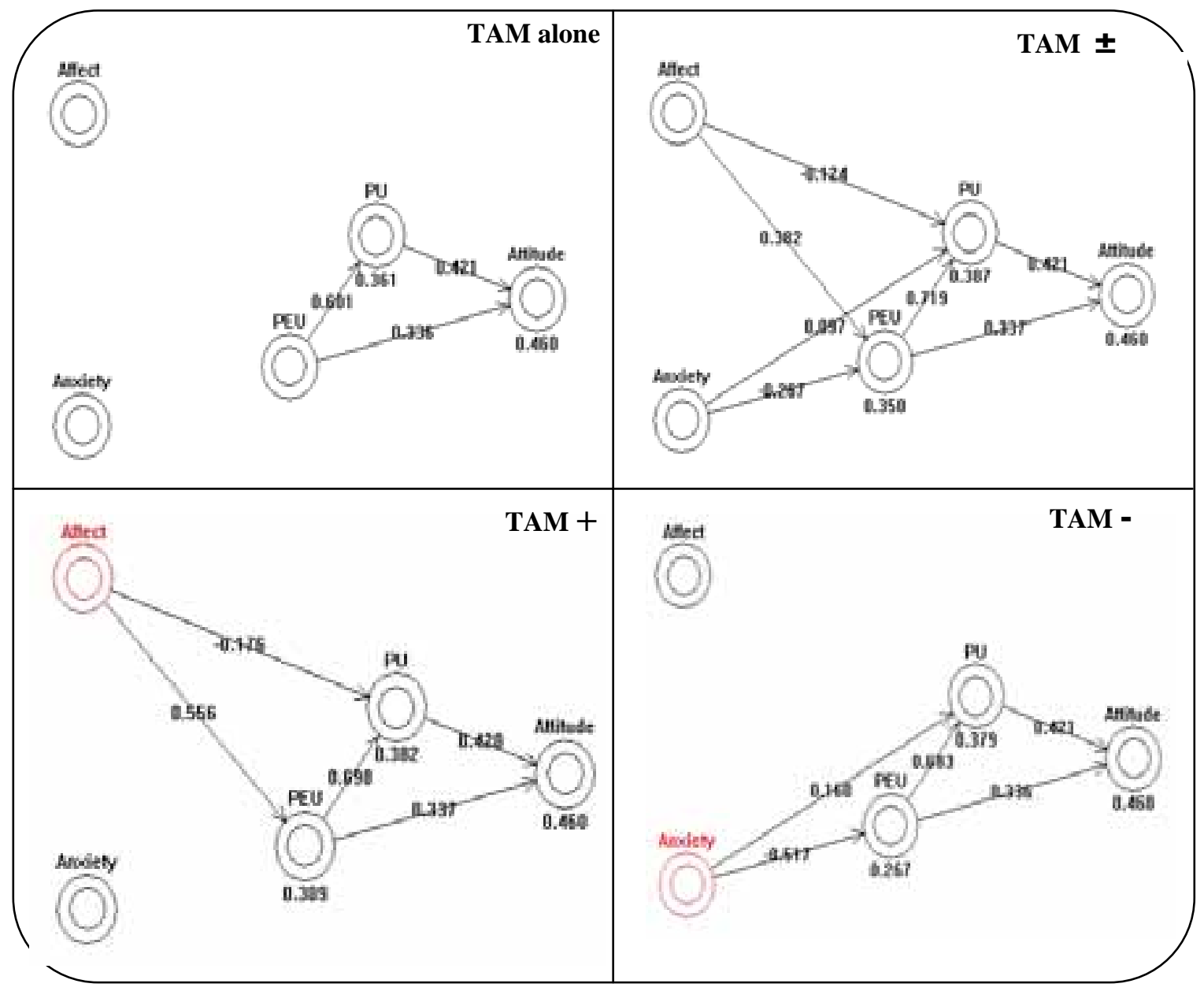

Figure 2. PLS simulations.

Together perceived ease of use and perceived usefulness explain $46 \%$ of the variances measured in relation to the students attitudes towards the OLS. It is evident though that perceived usefulness have contributed significantly more to attitudes than perceived ease of use. These results support hypotheses 1 and 2. Furthermore, hypothesis 3 which posited that PEU would influence PU was also supported with a strong path coefficient $(P C)=0.601$. Adding the impact of affect alone $(\mathrm{TAM}+)$ on the TAM shows a strong influence of AFF on PEU with a $\mathrm{PC}=0.556$. Doing the same thing but looking at the impact of anxiety alone (TAM -) we obtain a practically equally strong influence of ANX on PEU, with PC $=-0.517$. In both cases, the impact of PEU on PU is 
strengthened by approximately 15\%. Also, the influence of AFF and ANX on PEU was found to be positive and negative respectively as expected, therefore supporting hypotheses H4b and H5b.

Figure 2 also shows the influence of AFF and ANX on PU and in both cases this effect is small but significant with $\mathrm{PC}=-0.176$ and 0.16 respectively. What is interesting is the sign of the path coefficient which may suggest that the more a students felt good about the OLS the less they perceived it to be useful and the more they felt anxiety about the OLS the more they perceived it to be useful. This begs the questions: Do we have to limit the level at which students may like the OLS? Is liking an OLS bad for you? In any case, hypotheses H4a and H5a were not supported.

\section{Discussion and Conclusions}

The primary objective of this study was to investigate the influence that affect and anxiety have on perceived ease of use and perceived usefulness of an online learning system and the role they play in moderating the impact of perceived ease of use on perceived usefulness. All hypotheses with the exception of H4a and H5a were supported. In specific, the results seem to indicate that the emotional state of a student (whether that may be positive or negative) has no direct impact on perceived usefulness of an online learning system. In context, student's beliefs about the usefulness of the online learning system are not determined or influenced by their emotions towards that system. However, structured equation modeling simulations suggest that the influence of emotions on perceived usefulness is indirect through the perceived ease of use construct.

To that effect, four PLS runs (presented in figure 2) show that in the context of online learning system's usage, affect and anxiety work hand in hand. Their influence on PEU is practically equal and in opposite direction thereby implying that students using an online learning system under a mandatory setting and where their performance may influence their grade may feel anxiety and affect at the same time. This concept of "I like it but I am anxious" merits further investigation. This has major significant impact on how educational information systems in general and online learning systems in specific should be designed, implemented, used and evaluated. Designers should consider the use of an online learning system within an instructional and pedagogical setting. Too much fun using an online learning system may make students feel that it is not useful. Students may be thinking: "If I am enjoying it then it is not useful" and question the learning value of a game. Students in general may view learning as a not-so-fun thing to do. On the other extreme they may be thinking: "If I have anxiety in using the online learning system then it must be useful”. Whatever rational we may use, results lead us to a specific interesting conclusion: In a mandatory setting and while using an OLS, there seems to be a balance between affect (positive) and anxiety (negative) emotions occurring simultaneously. The balance or imbalance of the two is determined by the design of the online learning system and the pedagogy it is embedded in. With proper evaluation such as the model presented herein, one can optimize the impact to the effects/objectives that the designer is seeking.

Few limitations to this study exist and should be noted. First, the questionnaire approach is not free of subjectivity in the respondent and was taken at one point in time. User reactions change in time and may depend on the environment such as the classroom location and time of course. Second, caution must be taken in generalizing the results due to the fact that participants in this study were from different cultural background with different cultural beliefs influencing their perceptions and attitudes. In fact, what we are suggesting is a process of evaluation and understanding of the design-pedagogy-impact triangle for any online learning system. Most importantly, objective data on the usage of different components of online learning systems are rare. Future research should aim at designing controlled online learning environments where certain components of the course can be monitored with respect to frequency and duration of usage. This can provide greater credibility to future studies. 


\section{References}

Agarwal, R. \& Karahanna, E. (2000). Time flies when you're having fun: Cognitive absorption and beliefs about information technology usage. MIS Quarterly 24(4), 665-694.

Arkkelin, D. (2003). Putting Prometheus' feet to the fire: Student evaluations of Prometheus in relation to their attitudes towards and experience with computers, computer self-efficacy and preferred learning style. Syllabus2003 Proceedings.

Brosnan, M.J. (1998a). Technophobia: The psychological impact of information technology. New York: Routledge.

Brosnan, M.J. (1998b). The impact of computer anxiety and self-efficacy upon performance. Journal of Computer Assisted Learning, 14, 223-234.

Brown, I. J. T. (2002). Individual and technological factors affecting perceived ease of use of web-based learning technologies in a developing country. EJISDC, 9 (2), 1-15.

Chang, K. M., \& Cheung, W. (2001). Determinants of the intention to use internet/www at work: A confirmatory study. Information and management, 39 (1), 1-14.

Colley, A. M. \& Gale, T. M. (1994). Effects of gender role identity and experience on computer attitudes. Journal of Educational Computing Research, 10(2), 129-137.

Compeau, D. R., Higgins, C. A., \& Huff, S. (1999). Social cognitive theory and individual reactions to computing technology: A longitudinal study. MIS Quarterly, 23(2), 145-158.

Conlon, T. (1997). The Internet is not a panacea. Scottish Educational Review 29 (1), 30-38.

Davis, F. D. (1986). A technology acceptance model for empirically testing new end-user information systems: Theory and results. Doctoral Dissertation, Sloan school of management, Massachusetts Institute of Technology.

Davis, F. D. (1989). Perceived usefulness, perceived ease of use, and user acceptance of information technology. MIS Quarterly, 13(3), 319-339.

Davis, F. D., Bagozzi, R. P., \& Warshaw, R. P. (1989). User acceptance of computer technology: A comparison of two theoretical models. Management science, 35(8), 982-1003.

Debourgh, G. A. (1995). Learner and instructional predictors of student satisfaction in a graduate nursing program taught via interactive video conferencing and world wide web/internet. Doctoral dissertation, University of San Francisco.

Deci, E. L., \& Ryan, R.M. (1985). Intrinsic motivation and self-determination in human behavior. New York: Plenum.

Gefen, D., Karahanna, E. \& Straub, D. W. (2003a). Trust and TAM in online shopping: An integrated model. MIS Quarterly, 27(1), 51-90

Gefen, D., Karahanna, E. \& Straub, D. W. (2003b). Inexperience and experience with online stores: The importance of TAM and trust. IEEE Transactions on Engineering Management, 50(3), 1-15.

Gefen, D. \& Straub, D. W. (1997). Gender difference in the perception and use of e-mail: An extension to the technology acceptance model. MIS Quarterly, 21(4), 389-400.

Howard, S. G. \& Smith, D. R. (1986). Computer anxiety in management: Myth or reality? Communications of the ACM, 29(7), 611-615.

Ivari, J., \& Ervasti, I. (1994). User information satisfaction: IS implementability and effectiveness. Information and management, 27(4), 205-220.

Johanson, T. L. (1999). The virtual community of an online classroom: Participant's interactions in a community college writing class by computer mediated communication. Doctoral dissertation, Oregon State University. 
Johnson, D. S., Aragon, S. R., Shaik, N., \& Palma-Rivas, N. (2000). Comparative analysis of learners satisfaction and learning outcomes in online and face-to-face learning environments. Journal of Interactive Learning Research, 11(1), 29-49.

Keeney, L. R. (1999). The value of Internet commerce to the customer. Management Science, 45(4), 533542.

Keller, J. (1983). Motivational design of instruction. In C. Reigeluth (Ed.), Instructional design theories and models: An overview of their current status (pp. 386-434). Hillsdale, NJ: Erlbaum.

LaRose, R., Gregg, J., \& Eastin, M. (1998). Audiographic telecourses for the web: An experiment. Journal of Computer-Mediated Communications, 4 (2).

Lucas, H.C. \& Spitler, V.K. (1999). Technology use and performance: A field study of broker workstations. Decision Sciences, 30, 291-311.

Lucas, H.C. \& Spitler, V.K. (2000). Implementation in a world of workstations and networks. Information \& Management, 38(2), 119-128.

Nunnally, J.C. (1978). Psychometric theory ( $2^{\text {nd }}$ ed.). New York: McGraw-Hill.

Pedersen, P., \& Nysveen, H. (2003). Usefulness and self-expressiveness: Extending TAM to explain the Adoption of a mobile parking Services. In the proceeding of the $16^{\text {th }}$ Bled eCommerce Conference, Bled, Slovenia, June 9-11.

Saadé, R. (2003). Web based educational information system for enhanced learning, EISEL: Student assessment. Journal of Information Technology Education, 2, 267-277. Available at http://jite.org/documents/Vol2/v2p267-277-26.pdf

Saadé, R. \& Bahli, B. (2005) The impact of cognitive absorption on perceived usefulness and perceived ease of use in on-line learning: an extension of the technology acceptance model. Information \& Management, 42(2), 317-327.

Smith, B., Caputi, P., Crittenden, N., Jayasuriya, R. \& Rawstone, P. (1999). A review of the construct of computer experience. Computers in Human Behaviour, 15, 227-242.

Triandis, H. C. (1980). Values, attitudes and interpersonal behavior. Nebraska symposium on motivation, 1979: Beliefs, attitudes, and values, University of Nebraska Press, Lincoln, NE, 195-259.

Vallerand, R. J. (1997). Towards a hierarchical model of intrinsic and extrinsic motivation. Advances in Experimental Social Psychology, 29, 271-374.

Venkatesh, V. \& Davis, F. D. (2000). A theoretical extension of the technology acceptance model: Four longitudinal field studies. Management science, 46(2), 186-204.

Venkatesh, V. \& Morris, M. G. (2000). Why don't men ever stop to ask for directions? Gender, social influence, and their role in technology acceptance and usage behavior. MIS Quarterly, 24(1), 115-139. 


\section{Biographies}

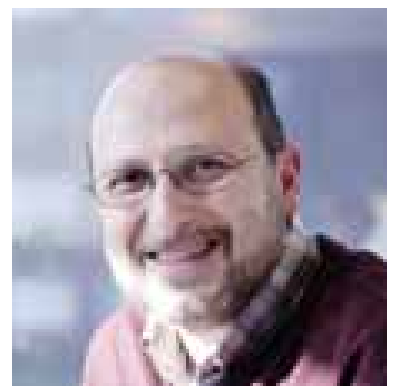

Dr. Raafat Saadé is an assistant professor at the DSMIS department, John Molson School of Business, Concordia University, Canada. Dr. Saadé obtained his Ph.D. in 1995 from Concordia University. He subsequently received the Canadian National Research Council postdoctoral fellowship, which he completed at McGill University in Montreal. He has been recognized twice as a North Atlantic Treaty Organization ASI award winner. Dr. Saadé has over 15 years of industrial experience (engineering, elearning and ehealth). He very active in research with over 25 peer refereed journal articles. Dr. Saadé has published in Information and Management, JITE, JIST, Computers in Human Behavior, IJIKM and Expert Systems with Applications. Dr. Saadé is also a co-founder of a non-profit organization (Viéquilibré) targeting the health, educational and spiritual needs of seniors, for a balanced life.

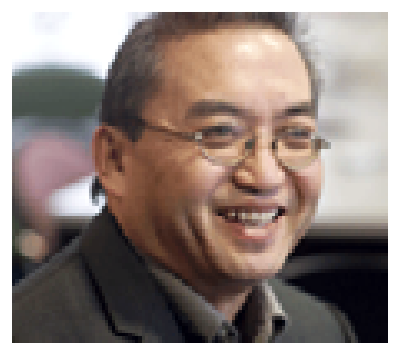

Dr. Dennis Kira is an associate professor at the DSMIS department, John Molson School of Business, Concordia University, Canada. He has been with the Faculty since 1983. He obtained his Ph.D. from University of British Columbia. Dr. Kira teaches System design, decision support systems, data management, data mining, internet related programming, and e-commerce His research activities include Ecommerce, web design, distance learning, decision making under uncertainty, neural networks, machine learning, and financial modeling. Dr. Kira has published in IEEE, ORQ and management science among other journals. 